\title{
Potential substitutes for povidone-iodine in ocular surgery
}

\author{
Piotr Kanclerz $\mathbb{D}^{1} \cdot$ William G. Myers ${ }^{2}$
}

Received: 14 December 2020 / Revised: 17 December 2020 / Accepted: 27 January 2021 / Published online: 16 February 2021

(C) The Author(s), under exclusive licence to The Royal College of Ophthalmologists 2021

Povidone-iodine (PVI) is a universally accepted antiseptic agent used in ophthalmic surgery with strong evidence for its efficacy [1]. Infrequently, PVI has been associated with complications including postoperative eye pain, persistent corneal epithelial defects, and an attendant risk of keratitis [2]. True allergies to iodine are rare, indeed most cases they are from direct toxicity, particularly in repeated procedures [1]. Insufficient preoperative antisepsis in patients with selfreported allergies to iodine has led to a high incidence of endophthalmitis cases [3].

Considering that 5.9 million intravitreal injections are performed annually in the United States, and that ocular antisepsis is crucial for every intraocular procedure, ophthalmologists should be familiar with the alternatives to PVI.

A perfect disinfectant should have a wide antimicrobial spectrum, manifest rapid action even in the presence of organic matter, and be nontoxic to the patient [4]. Commonly used antiseptic agents are presented in Table 1.

Several antiseptics are inappropriate due to their toxicity to the corneal epithelium [5]. Alcohol-containing disinfectants (e.g., $10 \%$ PVI in $70 \%$ alcohol, or $2 \%$ chlorhexidine in $70 \%$ isopropyl alcohol) cannot be applied. Chlorhexidine gluconate manifests corneal epithelial toxicity at concentrations over $1 \%$ [6], and at even lower concentrations when combined with benzalkonium chloride [7]. Inadvertent use of commercially available $0.5 \%$ chlorhexidine acetate $/ 0.1 \%$ cetrimide, instead of $0.05 \%$ chlorhexidine acetate, before intravitreal injection caused marked epithelial and stromal edema [8]. The application of concentrated PVI may lead to corneal staining at 24 hours after the application in healthy subjects [9], while additionally caused hyperemia [10]. In

\footnotetext{
Piotr Kanclerz

p.kanclerz@gumed.edu.pl

1 Hygeia Clinic, Gdańsk, Poland

2 Northwestern University, Chicago, IL, USA
}

clinical practice, PVI solutions have been widely used for several decades with adequate tolerability and safety.

Even low concentrations of disinfectants can harm corneal endothelial cells [11]. Naor et al. found PVI concentrations greater than $0.05 \%$ led to significant endothelial damage in bovine eyes [11]. Accidental use of chlorhexidine, cetrimide and cialit as an irrigating solution in cataract surgery led to immediate corneal oedema and bullous keratopathy [12]. Damage was also seen with detergent residue ( $6 \%$ nonionic ethoxylated fatty alcohol) from the irrigating cannula [13]. It is unlikely that a significant amount of disinfectant would inadvertently enter the anterior chamber and reach the endothelium during preoperative antisepsis [3, 14]. Viscoelastic use in cataract surgery may additionally reduce endothelial-cell damage [15].

Disinfectants are more effective under conditions where organic material is not present to inactivate free iodine. Using an iodine binding agar-plate model of bacteriacontaminated conjunctiva, Silas et al. showed that $0.7 \%$ PVP-I, used three consecutive times over two minutes, was the minimum concentration sufficient to reduce the bacterial population by the FDA-required standard of $3-\log _{10}$ [16] Lower concentrations of PVI are more effective, with a more rapid effect, due to increased levels of free iodine [1]. Interaction with organic substances reduces bactericidal free iodine. A disadvantage of using low PVI concentrations (such as $0.1-1.0 \%$ ) is that its disinfection capacity may be insufficient, necessitating iteration over $2 \mathrm{~min}$. This may be less practical for short-duration procedures such as intravitreal/intracameral injections [1].

High concentrations of antiseptics are toxic to the corneal epithelium [17], which is concentration dependent, but at low concentrations PVI is tolerated by most patients, even without anaesthesia. True antiseptic allergies, as determined by skinpatch testing, are extremely rare [18]. Allergic contact dermatitis is an uncommon adverse event after exposure to PVI, but physicians may misdiagnose simple contact dermatitis as an allergic reaction [18]. Chlorhexidine is a weak allergen but multiple exposures may lead to allergic contact dermatitis 
Table 1 Antiseptics of common use and their in vitro spectrum against Gram-positive and Gram-negative bacteria.

\begin{tabular}{llll}
\hline Group & Examples & $\begin{array}{l}\text { Gram- } \\
\text { positive }\end{array}$ & $\begin{array}{l}\text { Gram- } \\
\text { negative }\end{array}$ \\
\hline Biguanides & $\begin{array}{l}\text { Chlorhexidine } \\
\text { Picloxydine }\end{array}$ & $\mathrm{xxx}$ & $\mathrm{xx}$ \\
& $\begin{array}{l}\text { Polyhexamethylene } \\
\text { biguanide (Polyhexanide) }\end{array}$ & $\mathrm{xxx}$ & $\mathrm{xx}$ \\
& Octenidine & $\mathrm{xxx}$ & $\mathrm{xx}$ \\
Halogens & $\begin{array}{l}\text { Chlorines (e.g., sodium } \\
\text { hypochlorite) }\end{array}$ & $\mathrm{xxx}$ & $\mathrm{xx}$ \\
& $\begin{array}{l}\text { Iodophors (e.g., povidone- } \\
\text { iodine) }\end{array}$ & $\mathrm{xxx}$ & $\mathrm{xxx}$ \\
Alcohols & Ethanol & $\mathrm{xx}$ & $\mathrm{xx}$ \\
Phenolic & Triclosan & $\mathrm{xx}$ & $\mathrm{xx}$ \\
Compounds & & $\mathrm{x}$ & $\mathrm{x}$ \\
Other & Hydrogen peroxide & & \\
\hline
\end{tabular}

xxx: very strong; xx: strong; $\mathrm{x}$ : weak; 0: no activity.

Table created based on the findings from $[18,25]$.

[18]. Governmental warnings have been issued in recent decades warning of the risk of allergy to chlorhexidine applied on mucosal surfaces or in medical devices [19]. Rose et al. reported 252 cases of anaphylaxis to chlorhexidine in a perioperative setting in general surgical procedures [19]. Clinical features of ophthalmic exposure were an immediate (not delayed) onset of symptoms, and localized (not systemic) reactions. They concluded the incidence of anaphylaxis to chlorhexidine was low given that general surgical patients are commonly exposed, as chlorhexidine is the skin antiseptic of choice in general surgery.

Chlorhexidine has been used in Sweden in combination with intracameral cefuroxime since the introduction of this regimen in 1999 in over 2 million cataract procedures [20]. The postoperative endophthalmitis (POE) rate has remained around $0.020 \%$ in recent years, which could be attributed to employing intracameral cefuroxime and improved surgical routines. But in clinical practice the combination of intracameral cefuroxime with chlorhexidine as the antiseptic renders a real life POE rate of $0.020 \%$ [21, 22]. In Australia, aqueous chlorhexidine was administered in large series of intravitreal injections, and the endophthalmitis rates were similar to those using PVI [8].

Merani showed a single instillation of $0.5 \%$ chlorhexidine eye drops led to lower patient discomfort than that of 4\% PVI [2]. Nevertheless, it should be noted that preoperative topical anaesthesia was not used in that study and the concentration of PVI used was relatively high. In another investigation, 5\% PVI, $0.02 \%$ chlorhexidine and polyhexamethylene biguanide all provided similar reductions in bacterial counts before cataract surgery, but conjunctival infection, superficial punctate epitheliopathy, and ocular pain were more common in patients having undergone antisepsis with 5\% PVI [23].

The evidence on the use of other antiseptic alternatives is scarce. In a study $0.05 \%$ picloxydine to reduce the conjunctival bacterial load perioperatively in intravitreal injections (applications began three days prior to, and finished five days after the injections) [24]. Its efficacy for eliminating preoperative positive cultures was similar to that of tobramycin $0.3 \%$, while PVI was still used for conjunctival antisepsis just before the injection [24]. Hosseini et al. also reported that $0.02 \%$ polyhexanide was just as effective as $5 \%$ PVI or $0.02 \%$ chlorhexidine for reducing bacterial loads before cataract surgery [23].

We found no evidence to suggest that changing from PVI to other antiseptic agents was beneficial. In cases of poor PVI tolerance, applying povidone iodine at a lower concentration (if thought to be toxic), or the use of chlorhexidine $0.05 \%$ or $0.1 \%$ (if an allergy is suspected) are recommended. The optimum concentration and dosing regimen for chlorhexidine is yet to be determined. Disinfectant solutions other than PVI or chlorhexidine will require further investigations to show their potential utility in ocular surgery.

Acknowledgements We would like to thank Prof. Anders Behndig from the Department of Clinical Science/Ophthalmology, Umeå University Hospital, Sweden, for a critical discussion of our work.

Author contributions PK concept and design, data acquisition, drafting the manuscript; WGM interpretation of data for data for the work, revising for important intellectual content, drafting the manuscript.

\section{Compliance with ethical standards}

Conflict of interest PK reports non-financial support from Visim and Optopol Technology. WGM reports consulting fees from Leiters. The authors have no proprietary interest within the presented subject.

Publisher's note Springer Nature remains neutral with regard to jurisdictional claims in published maps and institutional affiliations.

\section{References}

1. Grzybowski A, Kanclerz P, Myers WG. The use of povidoneiodine in ophthalmology. Curr Opin Ophthalmol. 2018;29:19-32.

2. Oakley C, Allen P, Hooshmand J, Vote BJT. Pain and antisepsis after ocular administration of povidone-iodine versus chlorhexidine. Retina. 2018;38:2064-6.

3. Merani R, Hunyor AP. Endophthalmitis after intravitreal injections in patients with self-reported iodine allergy. Am $\mathrm{J}$ Ophthalmol. 2017;176:256-7.

4. Rutala WA, Weber DJ. Disinfection and sterilization in health care facilities: an overview and current issues. Infect Dis Clin North Am. 2016;30:609-37.

5. Oh JY, Yu JM, Ko JH. Analysis of ethanol effects on corneal epithelium. Invest Ophthalmol Vis Sci. 2013;54:3852-6. 
6. Hamill MB, Osato MS, Wilhelmus KR. Experimental evaluation of chlorhexidine gluconate for ocular antisepsis. Antimicrob Agents Chemother. 1984;26:793-6.

7. Burstein NL. Preservative cytotoxic threshold for benzalkonium chloride and chlorhexidine digluconate in cat and rabbit corneas. Invest Ophthalmol Vis Sci. 1980;19:308-13.

8. Merani R, et al. Aqueous Chlorhexidine for Intravitreal Injection Antisepsis: A Case Series and Review of the Literature. Ophthalmology. 2016;123:2588-94.

9. Ridder WH, Oquindo C, Dhamdhere K, Burke J. Effect of Povidone Iodine $5 \%$ on the Cornea, Vision, and Subjective Comfort. Optom Vis Sci. 2017;94:732-41.

10. Morton Grant W, Schuman, JS. Toxicology of the eye: effects on the eyes and visual system from chemicals, drugs, metals and minerals, plants, toxins and venoms; also systemic side effects from eye medications (4th Ed.). Springfield, IL: Charles C Thomas Publisher; 1993.

11. Naor J, Savion N, Blumenthal M, Assia EI. Corneal endothelial cytotoxicity of diluted povidone-iodine. J Cataract Refract Surg. 2001;27:941-7.

12. van $\mathrm{Rij} \mathrm{G}$, et al. Toxic keratopathy due to the accidental use of chlorhexidine, cetrimide and cialit. Doc Ophthalmol. 1995;90:7-14.

13. Nuyts RM, Edelhauser HF, Pels E, Breebaart AC. Toxic effects of detergents on the corneal endothelium. Arch Ophthalmol. 1990; 108:1158-62.

14. Green K, Livingston V, Bowman K, Hull DS. Chlorhexidine effects on corneal epithelium and endothelium. Arch Ophthalmol. 1980;98:1273-8.

15. Song J-S, Heo J-H, Kim H-M. Protective effects of dispersive viscoelastics on corneal endothelial damage in a toxic anterior segment syndrome animal model. Investigative Opthalmology Vis Sci. 2012;53:6164.

16. Silas MR, Schroeder RM, Thomson RB, Myers WG. Optimizing the antisepsis protocol: Effectiveness of 3 povidone-iodine $1.0 \%$ applications versus a single application of povidone-iodine 5.0. J Cataract Refract Surg. 2017;43:400-4.

17. Koerner JC, George MJ, Meyer DR, Rosco MG, Habib MM. Povidone-iodine concentration and dosing in cataract surgery. Surv Ophthalmol. 2018;63:862-8.

18. Lachapelle J-M. A comparison of the irritant and allergenic properties of antiseptics. Eur J Dermatol. 2014;24:3-9.

19. Rose MA, Garcez T, Savic S, Garvey LH. Chlorhexidine allergy in the perioperative setting: a narrative review. $\mathrm{Br} \mathrm{J}$ Anaesth. 2019;123:e95-e103.

20. Gili NJ, Noren T, Törnquist E, Crafoord S, Bäckman A. Preoperative preparation of eye with chlorhexidine solution significantly reduces bacterial load prior to 23-gauge vitrectomy in Swedish health care. BMC Ophthalmol. 2018;18:167.

21. Behndig A, Montan P, Stenevi U, Kugelberg M, Lundström M. One million cataract surgeries: Swedish National Cataract Register 1992-2009. J Cataract Refractive Surg. 2011;37: 1539-45.

22. Behndig A, et al. Endophthalmitis prophylaxis in cataract surgery: overview of current practice patterns in 9 European countries. J Cataract Refract Surg. 2013;39:1421-31.

23. Hosseini M, Peyman A, Narimani T. Comparison of the effects of povidone-iodine $5 \%$, polyhexamethylene biguanide, and chlorhexidine as a preoperative antiseptic in endophthalmitis prophylaxis in patients undergoing phacoemulsification cataract surgery. Adv Biomed Res. 2020;9:15.

24. Budzinskaya MV, Khalatyan AS, Strakhovskaya MG, Zhukhovitsky VG. Ocular flora in patients undergoing intravitreal injections: antibiotic resistance patterns and susceptibility to antiseptic picloxydine. Int J Ophthalmol. 2020;13:85-92.

25. Koburger T, Hübner N-O, Braun M, Siebert J, Kramer A. Standardized comparison of antiseptic efficacy of triclosan, PVPiodine, octenidine dihydrochloride, polyhexanide and chlorhexidine digluconate. J Antimicrob Chemother. 2010;65:1712-9. 